\title{
Aldous Huxley’in Ada adlı romanında ideoloji ve özgürlük
}

\section{Emrah OLUR'}

APA: Olur, E. (2019). Aldous Huxley'in Ada adlı romanında ideoloji ve özgürlük. RumeliDE Dil ve Edebiyat Araştırmaları Dergisi, (Ö6), 258-264. DOI: 10.29000/rumelide.648874

\section{$\ddot{\mathbf{O} z}$}

Bu çalışma, Aldous Huxley’in bir ütopya düşünü olan “Ada” isimli eserinde yansitılan özgürlüğü ve bu özgürlüğün devamı için dayatılan ideolojik aygıtları incelemektedir. Bu özgürlük algısının neden çıktığı, çıkmasına nelerin etki ettiği ve neye ulaşılmak istendiği gibi sorular incelenmekte ve romanda çeşitli güç mekanizmalarının etkisiyle oluşturulan ideolojik aygıtların özgürlük yanılsamasına neden olduğu tespit edilmektedir. Bu özgürlük yanılsamasının ortaya çıkmasında bireylerdeki psikolojik sorunların ne gibi etkileri olduğu da incelenmektedir. Bu romanda özgürlüğün seviyesi insanların mutluluk seviyelerine göre düz orantılı olarak artmaktadır. Başka bir ifade ile insanların korkularından kaçmaları ve onları mutlu edebilecek etkenlere yönelmeleri sağlanarak özgürlüğün yolu açılmaktadır. Bu etkenlerin ortaya çıkarılmasında ideolojik aygıtların kullanıldığı görülmektedir. Din, öz işlevinden uzaklaştırılarak, toplumu istenilen şekle getirebilmek için kullanılan bir aygıt olarak görülmektedir. Dini kendi çıkarları için kullanan mekanizmanın varlığı ve amaçları tespit edilmekte, kendi özgürlüklerinin gereksinimi olarak gücü elde etmeleri ve bunun için çeşitli ideolojik aygıtlar kullanarak toplumu gerçeklerden uzak tutmaları gerektiği çıkarımları ortaya koyulmaktadır. Ayrıca olguların zıttı ile var olursa tam anlaşılabileceği öngörülmekte, buna bağlı olarak da toplumsal bilinçaltını bastırmak için ideolojik mekanizmaların kullanıldığı anlaşılmaktadır. Korkularından uzaklaştırılarak sadece mutluluğa yönlendirilen toplum böylece öz benliğinden de uzaklaşmakta ve farkında olmadan oluşturulan sistemin bir uygulayıcısı konumuna düşmektedir. Tüm bu nedenlerden dolayı sunulan gerçeğin kendi haz duygusu olduğunu sanan birey, bunu sağlayan ideolojik aygıtlara bağlanmakta ve özgürlük yanılsamasına düşmektedir.

Anahtar kelimeler: Aldous Huxley, Ada, ideoloji, özgürlük, ütopya.

\section{Ideology and freedom in Aldous Huxley's novel, Island}

\begin{abstract}
This study examines freedom expressed in Aldous Huxley's Work Island and the ideological methods imposed for the continuity of the freedom. The questions such as why the idea of freedom has appeared, what has influenced it and what the goal has been, are discussed and it is found out that the ideological instruments designed with the impact of the various power mechanisms in the novel, cause illusion of freedom. The effects of the psychological problems of the individuals over occurrence of the illusion of freedom are analyzed as well. In this novel, the level of freedom increases in accordance with the happiness of the people indirectly proportional way. In other words, the way of freedom is opened by offering people to rescue from their fears and lean to the factors which may content them. It is seen that the ideological instruments are used in revealing these factors. Religion is gotten off its essence and is seen as an instrument used to put the society into the form desired.
\end{abstract}

1 Dr. Öğrencisi, Ankara Üniversitesi, Sosyal Bilimler Enstitüsü, İngiliz Dili ve Edebiyatı ABD (Ankara, Türkiye), emraholur@gmail.com, ORCID ID: 0000-0003-0975-4864 [Makale kaylt tarihi: 07.10.2019-kabul tarihi: 20.11.2019; DOI: $10.29000 /$ rumelide.648874] 


\begin{abstract}
The existence and the goals of the authority using religion within their benefits are determined and also it is propounded that they need to gain the power for their own freedom and keep the community away from the realities by using various ideological instruments in order to reach their target. Furthermore, it is predicted the phenomena may only be understood with their opposites, and in parallel with this it is seen that the ideological instruments are used to suppress the social subconsciousness. The community leaned to just the happiness by getting distracted from their fears, get estranged from their own identity and end up in the position of becoming the practitioners of the system set up. Due to all of these reasons, the individual thinking the presented reality as if it were his/her own pleasure, adheres to the ideological instruments providing this and falls into the illusion of freedom.
\end{abstract}

Keywords: Aldous Huxley, Island, Ideology, freedom, utopia.

\title{
Aldous Huxley'in Ada adlı romanında ideoloji ve özgürlük
}

Aldoux Huxley'nin son romanı Ada, en önemli distopyan romanlardan biri kabul edilen Cesur Yeni Dünya'dan farklı olarak, mutlu bir dünya hayallerini aktardığı ütopyan özellikler taşıyan bir romanı olarak bilinmektedir. Birçok ütopya düşünü içeren eser gibi, bir ada yerleşkesine kurulan yaşam, baskıcı bir yönetim yapısının olmadığı düşüncesinde, tam manasıyla bireyin özüne ve mutlak mutluluğa erebildiğine inanılan, özgür bir toplumu ve sistemi aktarmaktadır. Huxley'nin kurguladığı bu mutluluk, özgürlük, eşitlik ve ideal bir düzen ilkeleri, görünürde genel ütopya özelliklerini göstermektedir.

Genel olarak ideal bir dünya hayalinden oluşan ütopya, baskı altında yaşayan bireylerin daha huzurlu bir yaşam için tasarladıkları düşünlerdir. Ütopya kavramı aynı zamanda, Thomas More'un Ütopya'sında ki gibi ideal toplumları ya da Platon'un ideal devlet anlayışını savunan bir mekanizma olarak da yorumlanabilir. Bir başka ifade ile ideal bir yaşam, sistem ya da düzen kurgulanarak bir felsefe oluşturulur ve bunun akabinde de yeni bir ideoloji açığa çıkar. Bu fikrin en önemli noktası ise özgürlüktür. Bireyleri mutlu kılmanın da özgürlük ile var olabileceği düşüncesi vardır. O yüzden her ütopya kendi içerisinde bir ideolojiye sahip olabilmektedir. Bir fikrin amacı olarak da bir ideolojik kavramı destekleyebilir. Huxley'in bu romanında ulaşılmak istenen ütopya ise sınırsız özgürlük ve mutluluktur. Bu özgürlüğün destekçileri ise sistem yöneticileri ve din - Budizm - kavramıdır. İşte bu noktada da ideal yaşamın oluşması için hangi tür bir din anlayışı ya da felsefesi olursa olsun, hepsi birer ideolojik aygıt olarak bireyleri belirli kalıplar içerisinde tutmak zorundadır.

İdeoloji kavramın ilk olarak 18. yy'da Antoine Destult de Tracy tarafından "felsefi-bilimsel bir disiplin" (Özbek, 2011: 12) olarak kullanılsa da Marksizim ile birlikte 19. Yüzyılın sonlarına doğru anlamsal bir değere kavuşmuştur. Raymond Williams (1990), "Marxism ve Edebiyat" adlı kitabında ideolojiyi üç farklı şekilde tanımlar. Bunlardan ilki, belirli bir sınıf ya da gruba özgü inançlar olması, ikincisi ise düşsel inanç ya da yanlış düşüncelerdir. Sonuncusu ise anlam ve düşünce üretiminin genel süreci (s.48) olarak ifade edilmektedir. Louise Hitchcock da Kuramlar ve Kuramcılar adlı kitabında ideoloji kavramını Marx’ın bakış açısına göre istismarcı olarak şöyle yorumlar;

Ekonomik altyapı kendisini haklı çıkaran bir üstyapı tarafından desteklenmektedir. Bu üstyapının hedefi, sınıf farklılıklarının insanların değiştirmesinin mümkün olmadı̆̆ı ya da böyle bir arzu duymadıkları kapsayıcı bir gerçeklik olarak benimsenmesidir. Bu kültürel farklılıkların sanat ve (dini ile siyasi) inanç sistemleri yoluyla benimsetilmesi ideoloji olarak bilinir. (Hitchcock, 2013: 44).

Buradan yola çıkarak her iki alıntıda da Marksizm çerçevesinde ilk tanımlamalarında belirli ifadelerin, grupların ya da inançların dayatmaları olarak anlaşıldığını söyleyebiliriz. Hatta Marksist görüşe göre 
gerçeğe aykırı ve yanlış düşünceler ifadesi kullanılabilmektedir. Louise Hitchcock (2013), Marksizm’in fikirlerini tekrar yorumlayan Louis Althusser’in görüşlerini yorumlar ve onun ideoloji tanımını "üretim şekilleriyle ilişkimizi anlayabilmek için kendimize anlattığımız bir öykü - yani bizim yazarlığını yaptığımız bir öykü - olarak görür. Gerçek, nesnel bir dünya bizim için erişilebilir değildir, ancak onun temsilleri erişilebilirdir" (s.87) ifadesiyle verir. Althusser’in bu görüşüne göre ideoloji ile deneyimlerimizi anlayabilir ve yorumlayabiliriz. Böylelikle ideoloji, kendi hazlarını tamamlama ve ikna için kaçınılmaz bir gerçeklik ve gereklilik olmaktadır. Fakat bu gerçekliğin ideolojiye göre bir sistemin ve inancın sınırlamalarına bağlı olduğu ve hiçbir şekilde özgürlüğü veremeyeceği de anlaşılmaktadır. "İdeoloji, insani varlıkları birer toplumsal özne olarak kuran ve bu özneleri bir toplumdaki egemen üretim ilişkilerine bağlayan, yaşanan ilişkileri üreten anlamlandırma pratiklerini düzenlemenin bir yoludur" (Eagleton, 2011: 39). Sınırlamaları koyan bu yapının varlığı da o sistem içerisindeki ideolojiyi tanımlamamıza yardımcı olur. Bu tanımlamalara göre ideoloji de her zaman bir altyapı ve üstyapı olduğu çıkarımına varılmaktadır. Bu üstyapı her zaman toplumun dini, siyasi ve kültürel değerlerini belirlemektedir. Bir bakıma, olduğu gibi değil, üstyapının istediği ölçüde şekillendirilerek sunulmaktadır. Buna göre de üstyapının belirlediği ideolojiyi şekillendiren aygıtlar özünü kaybetmiş haldedir. Althuser’in sıkça bahsettiği kapitalist toplumlarda üretim ve süreç ideoloji ve baskı (devletin baskıcı aygıtları- polis, ordu, hukuk, hapishane vb.) ile meydana gelir. Althusser, bu sürecin oluşumunda üstyapının kullandığı din, siyaset, eğitim yapısı ve sanat gibi unsurları içeren mekanizmayı ise Devletin İdeolojik Aygıtları (DİA) olarak tanımlar. Söz konusu bu aygıtlar ile insanları her zaman istenilen yöne doğru bir yönlendirme mümkün olabilmektedir. "Bu teoride ideoloji, hâkim sınıfların ideolojisiyle birleştirilmiş kurumlar sistemi olarak ifade edilir. Bu kurumlar, öznelerin hâkim üretim ilişkilerini kabul etmelerini şart koşar" (Hirst, 2014: 230). Böylelikle özgürlük kavramı ideolojinin sınırları içerisinde din gibi siyaset gibi aygıtlarla anlamını yitirmektedir. “İdeolojiler bireyleri ‘özne’ler olarak çă̆ırır” (Özbek, 2011: 146). Özneler, ideolojilere tutkuyla bağlandıkları zaman özgürlük yanılsaması yaşarlar. Yine Özbek (2011), "Özgürlük yanılsaması, bir soruya akılsal bir yanıt üretme girişiminden kaynaklandığı için tutkuyla savunulur, ifadesini vurgular (s.155).” Böylece ideoloji yanlış da olsa sağlam argümanlarla desteklenirse gerçeklik algısı oluşturur, özgürlük yanılsaması ve geçici mutluluğu açığa çıkarır.

Bu yanılsama ve yanıltıcı mutluluk, Huxley'nin Ada romanında, Pala toplumunun yaşantısı ile aktarılır. Gazeteci Will Farnaby'nin bir deniz kazası sonrası nasıl karaya çıktığını hatırlamadığı bu adada yaşadığı gizemsel olaylar, karşılaştığı insanlar ve gözlemleri üzerinden gösterilir. Farnaby, geleneksel bir ütopya düşün adasından biraz farklı, hem kendi içinde özgün hem de ada dışındaki dünya ile kısmen ilişkileri olan, bağımsız, kendine özgü gelişmiş bir yapısı ve çatışmanın olmadığı barış içerisindeki bir adada açar gözlerini. Adanın kendine münhasır bu gelişmiş yapısı adanın önde gelenlerinden Raca ile İskoçyalı bilim insanı Dr. Robert’in birlikte ortaya koydukları bağımsızlık, mutluluk ve özgürlük ülküsü üzerine inşa edilir. Bu özgün ideal, kurucuları olan Dr. Robert’in batı modernizmi ve yöneldiği bilim ile Raca'nın doğuya ait geleneksel ahlakı, kültürü ve inançlarını birleştirerek tasarlanmıştır. Bu ideal, kendisini dış dünyadan, batı medeniyetinden ve küresel gelişmelerden soyutlamadan yeni bir yaşam ve toplum yapısı, aile yapısı, inanç, bilim ve özgürleşme oluşturur. Küresel sistemin tüm baskılarına karşın yeraltı kaynaklarını ve coğrafi zenginlikleri koruma çabası, bu ideal toplumun devamı için gereklilik olarak gösterilir. Adanın petrol kaynaklarını batılı küresel şirketlere satmayı kabul eden komşu askeri bir lider ile ilişkiler kuran Farnaby, her ne kadar gizliden yürütmek istese de adanın huzuru ve yaşadığı deneyim karşısında karasızlık yaşar ve psikolojik sorunlarından kurtulmaya başlar ve gerçek görevinden uzaklaşır.

Romanın ilk bölümü, Will Farnaby’ nin birkaç yıllık evli olduğu karısı ile yaşadığı sorunları anlattığı ve evi terk etmeye karar verdiği dönemi içermektedir. Farnaby, sıkıntılı bu ilişki sürecinde karısını birçok 
kez aldattığından bahsetmektedir. Kendince, yeni cinsel deneyimler yaşayarak ruhunu rahatlattığına inanmaktadır. Fakat bu tavırları karşısında sinirlenen karısı Molly, aşırı sürat sonucu arabasıyla kaza yapar ve ölür. Farnaby, bu ölümden dolayı sürekli kendisini sorumlu tutmaktadır.

Bu noktada Farnaby için ada, yalıtılmış bir mekâna benzerliğiyle beraber, hapishane ya da ruhsal bir terapi merkezini temsil etmektedir. Ada, mutluluk üzerine kurgulanmış sisteminde askeri yapılanması olmayan ve kendi özgün yönetimine sahip, barış içerisinde bir yapıdadır. Devletin baskıcı aygıtları bulunmamaktadır. Özellikle bu barışı getiren etkenin Budizm’in farklı bir kolu olan öğretilerden elde edildiği vurgulanır. Yani din bir düzen aygıtı olarak karşımıza çıkmaktadır. Meditasyonla iç huzuru sağlayarak sınırsız özgürlüğe kavuştuklarına inanılır. Cinsel ilişkilerde sınırlamaların olmadığı, her iki cinse de küçük yaşlardan itibaren özgürlüklerin verildiği bir ortamdır. Bu sistem içerisinde KEEKKarşılıklı Evlat Edinme Kulübü- adında 25 ailenin yer aldığı bir yapı ile çocukların birçok anne babası olmaktadır. Tanınan özgürlük sonucu istedikleri zaman istedikleri anne ve babanın yanına giderler. Bir başka deyişle acılardan ve korkulardan kaçmak için mekanlar oluşturulur. Bu sistemi oluşturan ve özgürlük öğretisini düzenleyen ise inandıkları dini olgulardır. Dini ritüeller insanlar üzerinde rahatlama yaratmakta ve mutluluk vermektedir. Adanın tüm sistemi de bunun üzerine kuruludur. Eğer insanlar mutlu olabiliyorlarsa özgürdürler görüşü hakimdir ve çocuklara ilk eğitim ylllarından itibaren bu fikir aşılanır. Kısacası adada özgürlüğün karşısında mutluluk vardır. "Ama yüce ya da bedensel, sahte ya da gerçek, mutluluk mutluluktur ve özgürlük tatlıdır (Huxley, 2015: 74)," ifadesiyle de ideolojinin temel dayanağı öğretilmektedir. Yürütülmek istenen sistem içerisinde insanlar mutlu olmalıdırlar. Bu mutluluğun getirisi ise sınırsız özgürlük ifadesini telkin ederek büyük bir rahatlama ve iç huzur sağlanmasıdır. Fakat özgürlük sadece dini ritüellere göre şekillenen bir yaşam tarzından kaynaklandığı için yanlış bir ifade olabilmektedir. Çünkü sınırsız özgürlük olamayacağı gibi ideolojik bir altyapısı olan özgürlük de olamaz. Özellikle sayfa 97'de "Mahayana" kolundan olduklarını söylerken "Tantra" ile iç içe oldukları ifade edilir. Tantra'da Hinduizmin bir koludur fakat özgürlüğü sunarken doygunluğun gerekliliğini öğretir. Özellikle cinsellik yolu ile doygunluğa erince tam bir mutluluk ve özgürlüğün geleceğini aktarır. Fakat buradan Althuser’in ifade ettiği Devletin İdeolojik Aygitlar'dan bir tanesi olan sistem için din kavramı ön plana çıkmaktadır. Din sistemin işleyişinde ideolojik bir ifade olmuştur. Aslında var olan bireylerin kandırılmasından öte bir şey değildir. Benimsedikleri dini kendi öz benliklerine ya da daimî mutlulukları için şekillendirmektedirler. Böylelikle bu din farklılaşmış, bir düzen aygıtı halini almıştır. Tüm dinler özünde iyi-kötünün ayrımı üzerinden kurulu ve bireylerin bunu anlayabilmesi için kötüyü de iyiyi de acıyı ve mutluluğu da bilmeye yöneltmektedir.

Yazar aslında bu yanılsamayı romanın bazı yerlerinde vurgulamaktadır. Özellikle Will'in okuduğu "Gerçek Üzerine Notlar" adlı kitapta mutluluğun acı olmadan anlaşılamayacağını aktarır. Her şeyin zittıyla beraber bir bütün oluşturduğunu ifade eden metin her mutluluğun ve özgürlüğün bir yanılsama olduğunu şöyle vurgular.

Olduğumu sandığım kişi ve özvarlığım - başka bir deyişle, acı ve acının bitimi. Olduğumu sandığım kişinin çektiği acıların aşağı yukarı üçte biri kaçınılmazdır. Bu acı insan olmanın doğası gereğidir; özgürleşme peşinde koşarken doğa yasalarına bağıml, geri döndürülmez zaman içinde, esenliğimize tümüyle kayıtsız bir evrende yaşlılığa ve ölümün kaçınılmazlığına doğru ilerlemeye mahkûm, sezgili ve bilinçli varlıklar olmamızın bedelidir. Acıların üçte ikisiniyse kendimiz yaratırız ve evrensel açıdan bakıldığında, bunlar kesinlikle gereksizdir (Huxley, 2015: 111).

Bu özgürlük yanılsaması, alıntıda, saf mutluluğun ve özgürlüğün aslında sonu ölüme doğru giden bir acıyı barındırdığını da gösterir. Uyguladıkları dini ritüellerin bir amacı da acıyı yok saymak ve onu yenmektir. Susila ve Will arasında geçen bir konuşmada Will'in, "Ölüm döşeğindekilere ne dersiniz? Ölümsüzlüğe kafa yormayıp işlerine mi baksınlar?” sorusuna karşılık “evet yaptı̆̆ımız tamı tamına bu. 
Bilincin uyanıklı̆̆ını sürdürmek; ölme sanatı bundan ibarettir” (Huxley, 2015: 308) der. İnsanları ölüm döşeğindeyken acılarından ve korkularından uzaklaştırmak. Tamamen kötü ya da acı yoktur kavramını savunmazlar. Fakat bir ideoloji gibi salt mutluluk ve özgürlügü savunurlar. Bu özgürlük duygusunu vermeye çocukluktan başlarlar. Bu nedenle de çocukluk dönemi, dayatılan sistem içerisinde, özgürlük yanılsamasının dikta edilerek aşılandığı en önemli evredir. Küçük yaşlardan başlayarak, özellikle de ilk okul yllarında, inanç öğretileri ve kurallar telkin edilir. Eğer sorunlu çocuklar tespit edilirse bir nevi rahatlama sağlayan, dini bir ritüeli de içerisinde barındıran, oyunlar öğreterek eğitirler ya da KEEK sistemi içerisinde, tüm aile yapılarında aynı telkin ile yönlendirilirler. Susila'nın "Bizim yirmi ailemizin hepsi bize uygundur (Huxley, 2015: 116)" ifadesi de tek tip yaşam şekli ve aile yapısının arzulanması ve sonucunda çocukluktan başlayan tek tip birey ve özgürlük yanılsamalarının açığa çıktığını göstermektedir. Bunu dikta olarak adlandırmayıp özgürlüğe götüren bir araç olarak kabullenmeleri de dikkat çekmektedir. Susila, kabullenilen bu dayatmayı, ada dışındaki ve adadaki aile yapısı ile karşılaştırarak şöyle anlatır:

İktidarsız bir bordro mahkûmu, doyumsuz bir diși, iki ya da (isteğe bağlı) üç küçük televizyon hastası alınız; Freudculuk ve sulandırılmış Hristiyanlık karışımında dinlendiriniz; sonra dört odalı bir apartman dairesine sıkıca kapatarak kendi suyunda on beș yıl hafif atește pișiriniz. Bizim yemek reçetemiz çok başka. Yirmi kadar cinsel yaşamında doyumlu çifti ve çocuklarını alınız; eşit ölçülerde bilim, sezgi ve neşe ekleyiniz; Tantrik Budizm'e batırarak üzerini kapatmadan açı havada, canlı sevecenlik ateşi üstünde dilediğiniz kadar pişiriniz. (Huxley, 2015: 116-117)

İfadelerde kullanılan kinayelerden çıkarımla, hiçbir şekilde dış dünya aile yapısını deneyimlemeyen bireyin, öğretilen sistemin üstünlüğünü koşulsuz kabul ettiği görülür. Oysa birey seçme hakkıyla öz benliğinin isteklerine varabilecek iken buradaki durum, gösterilen sistemi bireyin kendisine kabul ettirmesi olarak karşımıza çıkmaktadır. Dış dünyadaki dini tenkit ederken kendi sistemlerinde bağlı oldukları dini öğretileri doğru kabul etmeleri ise sorgulama ve seçmeden uzak, tamamen gösterileni kabul etmeye programlanmış bir sistem ideolojisini göstermektedir. Aslında yapı kendi içerisinde bireylere özgürlük adı altında seçme yetkisi verse de sunulan yapı tek ve üsten gelmedir. Bu haliyle de dayatılan her fikir ve öğreti gibi ideolojiye bağlıdır. Özellikle KEEK adını verdikleri birçok ailenin oluşturduğu bu yapıda çocuklar istedikleri aileyi tercih edebilseler de sunulan kadar özgürlük yaşamaktadırlar. Oysaki özgürlük soyuttur ve başka bir birey tarafindan sunulamaz. Susila bu konuşmanın devamında, "Sizin aileniz gibi kapalı, önceden belirlenmiş, zorunlu değil. Geniş, yazgısal olmayan, gönüllü bir aile (Huxley, 2015: 117)," ifadesiyle, vurgulanmak istenen temel meselenin, yaratılışa karşı bir tepki olarak mutluluğun önündeki sınırları kaldırmaktır savını ortaya atmaktadır. Sizin çocuklarınız belirli bir aile yapısı içerisinde ve sınırları belirli bir evde yaşıyor ifadesini verirken, kendi sistemlerinde ise aslında sevgiyi serbest bıraktıklarını vurgulamaktadır. Fakat buna rağmen ister bir aile olsun ister on aile olsun bu, sistemde mutluluk dayatmasının ve dini öğretilerin bir kurumsallaştırmasıdır. Her ne kadar ada da kurumsal bir yapı ve baskıcı bir sistem olmadığını iddia etseler de her din kendi içerisinde bir öğreti ve uygulama mekanizması taşımaktadır. Özünde var olan ya da özünden saptırılmış tüm inançlarda, korku, cesaret, sevgi, özgürlük ve esaret gibi zit duyguların özümsenmesi, bireyi tam anlamaya ve ulaşılması gerekilen öze yönlendirir. Böylelikle, dinin bu yönünü kendi anlayışları için kullanan sistemler, aslında siyasi bir rejim ile dayatılmayan olguları ya da ideolojiyi, bir din vasıtası ile insanlara pozitif yönden dayatmaktadırlar.

Adada bu sistemi devam ettirebilmek için ve dinde öğütlenen mutluluğun da üzerinde gerçeğe ulaşabilmek için bazı deneyler sonucu birtakım ilaçlar elde etmişlerdir. Bu noktada bireylere "Mokşa" adında bir ilaç verilmekte ve insanların Nirvana dediğimiz en ulvi düzeyde bir mutluluk yaşaması sağlanmaktadır. Hem bu öyle bir mutluluktur ki yeri geldiğinde acıyı da yaşarsınız. Doktor Robert ulaşılan bu özgürlüğü de şu şekilde ifade etmektedir; 


\begin{abstract}
"Özgürleşme," diye yeniden başladı Dr. Robert, "Acı ve ıstırabın sona erişi, olduğunuzu sandığınız kişilikten sıyrılarak gerçek kişiliğinize, özünüze dönüşmeniz. Mokşa ilacı sayesinde, bir an için bile olsa, gerçek yaradılışınızı, aslında hep var olan özünüzü yaşamanın coşkusunu tadacaksınız. Ne sonsuz bir mutluluk! Ancak her şey gibi bu sonsuz mutluluk da aslında geçicidir. Her şey gibi o da biter. Peki, bu mutluluk bittiğinde, yaşadığınız bu deneye ne olacak? Gelecekte mokşa ilacının size yaşatacağı tüm benzer deneylere ne olacak? Onları bir kukla gösterisi gibi izleyip sonra işinize gücünüze dönecek ve olduğunuzu sandığınız tutarsız, yanılgılar içindeki kişiliğin doğrultusunda mı davranacaksınız? Yoksa somut gerçeği bir an olsun gördükten sonra, tüm varlığınızı, tüm yaşamınızı o olağanüstü özvarlığınızı bulma uğraşına mı adayacaksınız? Biz, görmüş geçirmiş kişiler öğretilerimizle ve pala toplumsal düzeniyle, sizlere yalnızca birtakım yöntemler öğretir, gerçeğe uyanmanız için bazı fırsatlar sağlayabiliriz. Mokşa ilacı da sizlere yalnız bir dizi coşku veren görüntü, birkaç saatlik aydınlanma ve özgürlük sunar (Huxley, 2015: 218-219).
\end{abstract}

Dr. Robert'in söylemek istedikleri aslında vurgulamak istediklerimizi desteklemektedir. Çünkü bir ilacın en fazla bir iki saatlik vereceği mutluluktan sonra yine siz hayatınıza döneceksiniz. Fakat burada asıl önemli nokta ise ilaç ile herkesi bu sistemin bir parçası haline getirme çabasıdır. Tüm bu deneyler bunun ürünüdür ve bu sisteme hizmet etmektedir. Günümüz gerçek hayatında sağllk sektörünün insanları geçici tedaviler ile iyileştirdiği ve mutlu ettiği haplara ve bağımlılığa çok benzemektedir. Belirli bir noktadan sonra birey o sisteme ait olmayı ihtiyaç ve zorunluluk olarak görür. Burada, "acı ve ıstırabın sona erişi” ifadesi ile insanları korkularından uzaklaştırmayı vadediyorlar. Mokşa hapının verdiği haz duygusu gerçek hayatta olup biten ya da olabilecek olan bütün korkuları geçici olarak unutturmaktadır. Bu süreç sonunda insanların bu haplara bağımlı hale gelmesi sonucu gerçek ile gerçek olmayan arasında bir karmaşa yaşanır. Çünkü birey artık mutluluğu gerçek olarak algılamaktadır. Bunların dışında, tüm dinlerin ve sistemlerin her insanda aynı etkiyi yapması ve her insanın ona bağlanması imkânsızdır. İște bu noktada adayı yönlendiren üstyapı, ideolojisi gereği herkesi aynı mutluluk düzeyinde tutmak zorundadır. Bu sebepten dolayıdır ki, dini ritüellerle ulaşılamayan noktalara kendi yaptıkları uyuşturucu ilaçlar ile ulaşmaktadırlar. "-özgürlüğe değer veren her toplum için geleceğin uyurgezerlerini önceden belirlemek çok yaşamsal bir önem taşır. Bir kez belirlediler mi, hipnotizma araculı̆ıyla sistemli bir biçimde onları eğiterek, özgürlük düşmanlarmm etkisine girmemelerini sağlayabiliriz (Huxley, 2015: 263)," ifadesi ile açık ve net bir şekilde ilaç kullanan bireyler, uyurgezer ve kullanılabilir kişiler olarak tanımlanır. En başta da belirtildiği gibi içerisinde bir ideoloji barındıran hiçbir hareket sınırsız özgürlük sağlayamayacağı gibi aynı zamanda kendi sistemlerine de bireyleri köle ederler. Aslında Mahayana Budizm'inde bu şekilde ilaçlar ve bu tür sistemler bulunmamaktadır. Onu şekillendirerek kendi ideolojilerine uygun hale getirmek isteyen bireyler vardır.

$\mathrm{Bu}$ çalışmanın sonucu olarak, Mahayana Budizm’i ile kendilerine bir yaşam şekli oluşturmuş ada halkının tek amacı dış dünyanın içerisinde bulunduğu kaos ortamından uzak, barış ve mutluluk içerisinde özgürce yaşamaktır. Kendileri bunu sonsuz özgürlük olarak tanımlamalarına rağmen bu anlayış bir ideolojinin göstergesidir. Bu ideolojinin aygıtı özünden saptırılmış dindir. Bu dinin yönlendirdiği süreç ise insanları korkularından uzaklaştırarak mutluluğu tattırmak. Böylece insanlar haz duygularını tatmin etmiş ve o dini öğretilere bağımlı hale gelmiş olacaklardır. Böylece üstyapı, altyapıyı adanın ve yönetim gücünün korunması noktasında kullanmaktadır. Buradan çıkan sonuç, üstyapı, eğer bu birlikteliği sağlayamaz ise hem ada ellerinden gidecektir hem de yönetim gücü. Tüm bu göstergeler ışığında, özgürlüğün seviyesi insanların mutluluk seviyelerine göre doğru orantılı olarak artmaktadır. Başka bir ifade ile insanların korkularından kaçmaları ve onları mutlu edebilecek etkenlere yönelmeleri sağlanarak özgürlüğün yolu açılmaktadır. Bu etkenlerin ortaya çıkarılmasında ideolojik aygıtların kullanıldı̆̆ı görülmektedir. Din, öz işlevinden uzaklaştırılarak, toplumu istenilen şekle getirebilmek için kullanılan bir aygıt olarak görülmektedir. Dini kendi çıarları için kullanan mekanizmanın varlığı ve amaçları tespit edilmekte, kendi özgürlüklerinin gereksinimi olarak gücü elde etmeleri ve bunun için çeşitli ideolojik aygitlar kullanarak toplumu gerçeklerden uzak tutmaları 
gerektiği çıkarımları ortaya konulmaktadır. Ayrıca olguların, karşıtları ile var olurlarsa tam anlaşlabileceği öngörülmekte, buna bağlı olarak da toplumsal bilinçaltını bastırmak için ideolojik mekanizmaların kullanıldığı anlaşılmaktadır. Korkularından uzaklaştırılarak sadece mutluluğa yönlendirilen toplum böylece öz benliğinden de uzaklaşmakta ve farkında olmadan oluşturulan sistemin bir uygulayıcısı konumuna düşmektedir. Tüm bu nedenlerden dolayı sunulan gerçeğin kendi haz duygusu olduğunu sanan birey, bunu sağlayan ideolojik aygitlara bağlanmakta ve özgürlük yanılsamasına düşmektedir. Burada ayrıca ideoloji kavramı Marx’ın "gerçeği olduğu gibi yansıtmamak (Mardin, 2015: 15)" anlayışıyla da örtüşmektedir. İnsanlara sürekli mutluluğu telkin etmelerindeki amaçları ise düzeni koruma çabasıdır.

\section{Kaynakça}

Eagleton, T. (2011). İdeoloji. Muttalip Özcan (Çev.). İstanbul: Ayrıntı.

Hirst, Q. P. (2014). Althusser ve İdeoloji Teorisi. Can Şahan (Ed.) İdeoloji Üzerine. Can Şahan (Çev.). İstanbul: Pales.

Hitchcock, L. (2013). Kuramlar ve Kuramcılar. Seda Pekşen (Çev.). İstanbul: İletişim.

Huxley, A. (2015). Ada. Seniha Akar (Çev.). İstanbul: İthaki.

Mardin, Ş. (2015). İdeoloji. İstanbul: İletişim.

Özbek, S. (2011). İdeoloji Kuramları. İstanbul: Notos.

Williams, R. (1990). Marksizm ve Edebiyat. Esen Tarım (Çev.). İstanbul: Adam. 